\title{
Social class and ischaemic heart disease: use of the male:female ratio to identify possible occupational hazards
}

\author{
R F HELLER, H WILLIAMS, AND Y SITTAMPALAM \\ From the Department of Community Medicine, St Thomas's Hospital Medical School, London SE1, UK
}

SUMMARY In England and Wales there has been an increasing excess of ischaemic heart disease death rates among men and women of social classes IV and V compared with those in classes I and II and this excess is greater in young than in old adults. The male excess over women in IHD death rates is much greater in social classes I and II than in classes IV and V. Although men in professional occupations are at low risk for IHD compared with men in other ocupations, women married to professional men are at an even lower risk compared with other women. Also, women married to men in unskilled occupations have relatively higher IHD rates than their husbands. These patterns are not seen for "all causes," cerebrovascular disease, chronic bronchitis, or stomach cancer, where the social class mortality gradients are similar in men and women. There may thus be factors associated with professional occupations that increase the risk of IHD despite the relatively low death rates of men engaged in them. In addition there may be factors operating in women in social classes IV and V that put them at a particularly high risk for the development of IHD.

Ischaemic heart disease (IHD) has often been considered as a disease of the "upper" social classes, although now there is a considerable amount of evidence suggesting the reverse. ${ }^{1}$ The reason for the association between IHD and social class may be a risk directly from some occupational exposure, from some lifestyle associated with particular occupations, or from a more general lifestyle associated with the broader social class grouping. Since the social class of married women is assigned on the basis of their husbands' occupations, and since husbands and wives may share some of the lifestyle characteristics that go to make up social class, an examination of the relative differences between men and women of the same social class may be used to identify hazards associated with the particular occupation of the husband. ${ }^{2-4}$

We have explored the male:female ratio for IHD in social classes, socioeconomic groups, and occupation orders in an attempt to identify particular occupations that may be important in aetiology of IHD.

\section{Method}

We used the Occupational Mortality Decennial Supplements for England and Wales from 1930-2 (1931), 1950-2 (1951), 1960-2 (1961), and 1970-2 (1971) to examine the male:female ratios for the disease categories that probably correspond most closely to ischaemic heart disease (IHD) (ICD 93, 94 in 1931; ICD 420-422, 440-447, in 1951 and 1961; ICD $410-414,400-404,420-429$ in 1971) at different age groups in different social classes. These categories are similar to those used previously when trends over time have been examined, to reduce bias introduced by changing ICD revisions ${ }^{5}{ }^{6}$ and include acute and chronic heart disease as well as hypertension. For most analyses we have combined the data for social classes IV and V and classes I and II to increase numbers and reduce the influence of alterations in the proportions of the population in various social classes over time. For the 1971 data we have also computed male:female ratios for each 
individual socioeconomic group and occupation order. This last analysis (which for IHD, since only one ICD revision is involved, was restricted to ICD 410-414) has been performed using both individual 10 year age bands and also using the standardised mortality ratio (SMR) separately in men and women as a single summary figure reflecting mortality rates unaffected by the different age structure in the different populations and sexes. The SMR gives an idea of the position of members of one group relative to other men or women; since the overall SMR is 100 for both sexes, the ratio betwen them is 1 and thus does not reflect the sex difference in actual death rates. Also for the 1971 data we have examined all causes, cerebrovascular disease (ICD 430-438), chronic bronchitis, emphysema, and asthma (ICD 490-493), and stomach cancer (ICD 151) in the same way. These disease categories were chosen as relatively large causes of death affecting both men and women: cerebrovascular disease in view of the many aetiological similarities with IHD, chronic lung disease in view of the many known associations with occupation and social class, and stomach cancer as an example of a cancer that also has a strong social class gradient.

\section{Results}

Figure 1 summarises the social class gradient for IHD in men and women. The excess in classes IV/V is considerably greater at younger ages, and there has never been an excess of IHD in classes I/II in all age groups. The class gradient has, however, widened consistently since 1951. Figure 2 shows the male:female ratios in the same years. There is a consistently greater male excess for IHD in social class I/II than IV/V. This excess is greater in the middle age groups and increased between 1931 and 1961 (with 1971 being similar to 1961).

Table 1 shows that men of social classes I and II have a relative excess of IHD compared with women; despite this they have a low SMR compared with other men. A male excess of this magnitude in classes I and II is not seen for the other diseases studied. When individual socioeconomic groups are examined (table 2) self employed professionals appear to be at the greatest risk compared with their spouses, whereas agricultural workers are at a particularly low risk compared with their wives. Again, where the male excess is large the SMR for IHD in men alone is often low, although employers in industry, junior non-manual workers, and members of the armed forces have high rates of IHD both compared with their wives and with men in other occupations. Conversely, the female SMRs are higher than the male of the same socioeconomic
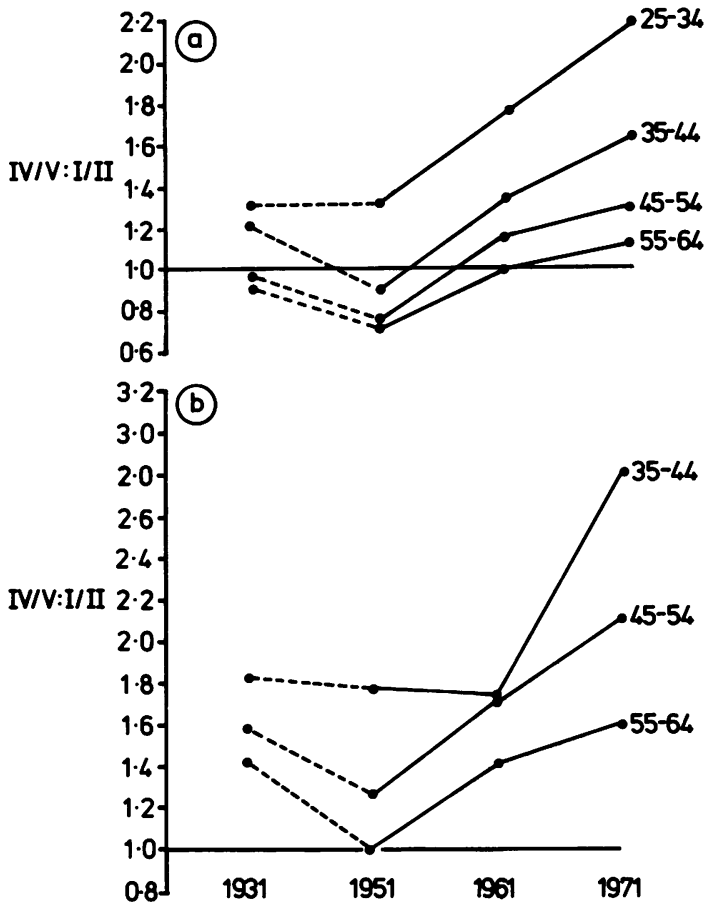

Fig 1 Ratio of ischaemic heart disease death rates in England and Wales between social classes IV/V and I/II in (a) men and (b) women.

Table 1 SMRs for men $(M)$ and women $(W)$ and the ratio between men and women

\begin{tabular}{|c|c|c|c|c|c|}
\hline & & \multicolumn{4}{|c|}{ Social class } \\
\hline & & $I$ & $\boldsymbol{I I}$ & $I V$ & $\boldsymbol{V}$ \\
\hline Ischaemic heart disease & $\begin{array}{l}\mathbf{M} \\
\mathbf{W} \\
\text { (Ratio) }\end{array}$ & $\begin{array}{c}88 \\
58 \\
(1 \cdot 52)\end{array}$ & $\begin{array}{c}91 \\
77 \\
(1 \cdot 18)\end{array}$ & $\begin{array}{l}108 \\
123 \\
(0 \cdot 88)\end{array}$ & $\begin{array}{l}111 \\
146 \\
(0 \cdot 76)\end{array}$ \\
\hline Cerebrovascular accident & $\begin{array}{l}\mathbf{M} \\
\mathbf{W} \\
\text { (Ratio) }\end{array}$ & $\begin{array}{c}80 \\
76 \\
(1.05)\end{array}$ & $\begin{array}{c}86 \\
84 \\
(1.02)\end{array}$ & $\begin{array}{l}111 \\
124 \\
(0 \cdot 90)\end{array}$ & $\begin{array}{l}136 \\
139 \\
(0.98)\end{array}$ \\
\hline Bronchitis, emphysema, asthma & $\begin{array}{l}\text { M } \\
\mathbf{W} \\
\text { (Ratio) }\end{array}$ & $\begin{array}{c}36 \\
41 \\
(0.88)\end{array}$ & $\begin{array}{c}51 \\
60 \\
(0.85)\end{array}$ & $\begin{array}{l}128 \\
130 \\
(0 \cdot 98)\end{array}$ & $\begin{array}{l}138 \\
189 \\
(0 \cdot 73)\end{array}$ \\
\hline Stomach cancer & $\begin{array}{l}\mathbf{M} \\
\mathbf{W} \\
\text { (Ratio) }\end{array}$ & $\begin{array}{c}50 \\
60 \\
(0.83)\end{array}$ & $\begin{array}{c}66 \\
84 \\
(0.79)\end{array}$ & $\begin{array}{l}125 \\
123 \\
(1 \cdot 02)\end{array}$ & $\begin{array}{l}147 \\
145 \\
(1.01)\end{array}$ \\
\hline All causes & $\begin{array}{l}\mathbf{M} \\
\mathbf{W} \\
\text { (Ratio) }\end{array}$ & $\begin{array}{c}77 \\
82 \\
(0.94)\end{array}$ & $\begin{array}{c}81 \\
87 \\
(0.93)\end{array}$ & $\begin{array}{l}114 \\
119 \\
(0.96)\end{array}$ & $\begin{array}{l}137 \\
135 \\
(1 \cdot 01)\end{array}$ \\
\hline
\end{tabular}

group for several categories, leading to a low male:female ratio among the group going to make up social classes IV and V. 


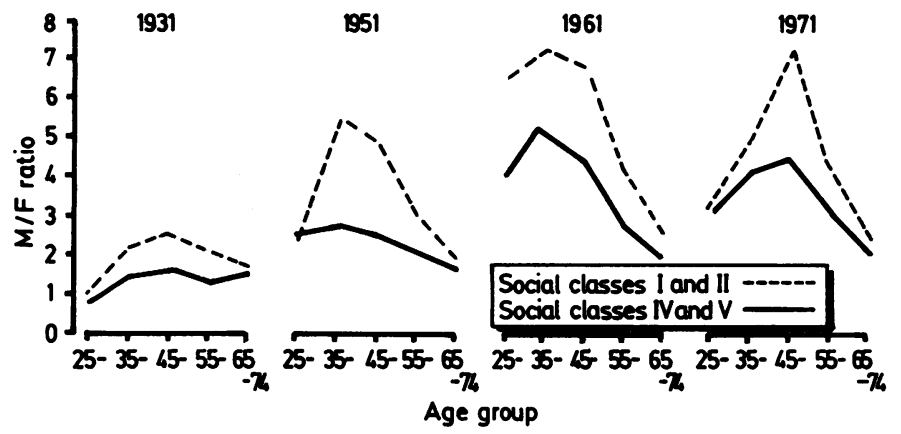

Fig 2 Ratio of ischaemic heart disease death rates in England and Wales between men and women in social classes I/II and IV/V.

Table 2 Standardised mortality ratio for ischaemic heart disease in each socioeconomic group (SEG) for men and women and the ratio between them

\begin{tabular}{|c|c|c|c|c|}
\hline SEG & Job description & Men & Women & $\begin{array}{l}\text { Male:female } \\
\text { ratio }\end{array}$ \\
\hline $1 \cdot 1 \& 1 \cdot 2$ & Employers in industry & 108 & 98 & $1 \cdot 10$ \\
\hline $2 \cdot 1 \& 2 \cdot 2$ & Managers in industry & 91 & 71 & $1 \cdot 28$ \\
\hline 3 & Professionals (self employed) & 81 & 47 & $1 \cdot 72$ \\
\hline 4 & Professionals (employers) & 86 & 60 & 1.43 \\
\hline $5 \cdot 1$ & Ancillary workers & 86 & 71 & $1 \cdot 21$ \\
\hline $5 \cdot 2$ & Foremen, supervisors(non-manu & al) 80 & 67 & $1 \cdot 19$ \\
\hline 6 & Junior non-manual & 117 & 88 & $1 \cdot 33$ \\
\hline 7 & Personal service & 126 & 117 & 1.08 \\
\hline 8 & Foremen and supervisor (manua & 1) 88 & 97 & 0.91 \\
\hline 9 & Skilled manual & 112 & 134 & 0.84 \\
\hline 10 & Semiskilled manual & 111 & 132 & 0.84 \\
\hline 11 & Unskilled manual & 116 & 152 & 0.76 \\
\hline 12 & Own account workers & 80 & 72 & $1 \cdot 11$ \\
\hline 13 & Farmers, employers, managers & 93 & 115 & 0.81 \\
\hline 14 & Farmers, own account & 58 & 67 & 0.87 \\
\hline 15 & Agricultural workers & 82 & 133 & 0.62 \\
\hline 16 & Member of the armed forces & 146 & 108 & $1 \cdot 35$ \\
\hline
\end{tabular}

The pattern for IHD differs from that for the other diseases studied where in no socioeconomic group is there a large male excess, apart from in self employed professionals where the male:female ratio for cerebrovascular disease and all causes mortality is 1.28 and 1.43 respectively.

Table 3 shows that among the occupation orders, men in XXI, XXIV, XXV, and XXVI (clerical workers, administrators and managers, professional workers, and members of the armed forces) have the greatest excess relative to their wives. Of these groups, the SMR for men alone is also high in the clerical workers and the members of the armed forces. Again, several occupation orders show a high SMR in women and a low male:female ratio.

\section{Discussion}

The excess of IHD seen in social classes IV/V is greater in younger than older adults in both men and
Table 3 Standardised mortality ratio for ischaemic heart disease in each occupation for men and women and the ratio between them

\begin{tabular}{|c|c|c|c|c|}
\hline $\begin{array}{l}\text { Occupation } \\
\text { order }\end{array}$ & Job description & Men & Women & $\begin{array}{l}\text { Male:female } \\
\text { Ratio }\end{array}$ \\
\hline I & Farmers, foresters, firemen & 80 & 108 & 0.74 \\
\hline II & Miners and quarrymen & 132 & 202 & 0.65 \\
\hline III & Gas, coke, and chemical workers & 111 & 141 & 0.79 \\
\hline IV & Glass and ceramic workers & 100 & 100 & $1 \cdot 00$ \\
\hline $\mathbf{V}$ & $\begin{array}{l}\text { Furnace, forge, foundry rolling } \\
\text { mill workers }\end{array}$ & 112 & 143 & 0.78 \\
\hline VI & Electrical and electronic workers & 115 & 109 & 1.06 \\
\hline VII & Engineering and applied trades & & & \\
\hline & NEC & 106 & 118 & 0.90 \\
\hline VIII & Woodworkers & 95 & 105 & 0.90 \\
\hline IX & Leather workers & 119 & 108 & $1 \cdot 10$ \\
\hline $\mathbf{X}$ & Textile workers & 118 & 115 & 0.76 \\
\hline $\mathbf{X I}$ & Clothing workers & 112 & 105 & $1 \cdot 07$ \\
\hline XII & Food drink and tobacco workers & 107 & 122 & 0.88 \\
\hline XIII & Paper and printing workers & 99 & 90 & $1 \cdot 10$ \\
\hline XIV & Makers of other products & 88 & 103 & 0.85 \\
\hline $\mathbf{X V}$ & Construction workers & 101 & 123 & $0 \cdot 82$ \\
\hline XVI & Painters and decorators & 107 & 121 & 0.88 \\
\hline XVII & Drivers of stationary engines vans & & & \\
\hline & etc & 105 & 134 & 0.78 \\
\hline XVIII & Labourers NEC & 118 & 162 & 0.73 \\
\hline $\mathbf{X I X}$ & $\begin{array}{l}\text { Transport and communication } \\
\text { workers }\end{array}$ & 111 & 129 & $0 \cdot 86$ \\
\hline $\mathbf{X X}$ & $\begin{array}{l}\text { Warehousemen, storekeepers, } \\
\text { packers, bottlers }\end{array}$ & 113 & 121 & 0.94 \\
\hline $\mathbf{X X I}$ & Clerical workers & 116 & 80 & 1.45 \\
\hline XXII & Sales workers & 93 & 79 & $1 \cdot 18$ \\
\hline XXIII & $\begin{array}{l}\text { Service, sport, and recreation } \\
\text { workers }\end{array}$ & 115 & 107 & 1.08 \\
\hline $\begin{array}{l}\text { XXIV } \\
\mathbf{X X V}\end{array}$ & $\begin{array}{l}\text { Administrators and managers } \\
\text { Professional, technical workers, }\end{array}$ & 86 & 64 & $1 \cdot 34$ \\
\hline & artists & 85 & 60 & 1.42 \\
\hline XXVI & Armed forces & 146 & 108 & 1.35 \\
\hline
\end{tabular}

NEC $=$ Not elsewhere clasified.

women, and also the excess of IHD seen in men compared with women is greater in the middle age groups. These age differences, together with the observations that rates of IHD both increased faster in the young ${ }^{5}$ and have now started to decline faster in the young, ${ }^{7}$ suggest that young adults may be relatively more vulnerable to environmental influences than older people. This illustrates the need 
to examine age specific rates rather than relying purely on the SMR which, in a disease that increases in frequency with age, is heavily weighted towards the experience of the older age groups. To make sure that an age effect did not influence our within occupation group analysis of male:female differences (as women will tend to be older than men within each class or occupation category) we examined the patterns with age specific rates as well as using SMR's: essentially the same picture was seen although numbers in some groups were small.

The social gradient for IHD is much stronger for women than it is for men. Despite a lower rate of IHD in men of social classes I and II compared with men of classes IV and V, these men are at relatively high risk for IHD compared with their wives and, conversely, women in classes IV and $V$ are at a relatively high risk compared with their husbands. For the other disease categories examined, although strong social gradients exist, they are similar in men and women and the relative differences between husbands and wives are not seen.

The data suggest that there may be a particular hazard for the development of IHD associated with the occupations going to make up social classes I and II. If just general class associated lifestyles were to provide a risk we would expect husbands and wives to share in this risk. That wives of men in social classes I and II are not at as high a risk as their husbands suggests that it is what happens at work that produces a risk. Alternatively, a high rate of IHD in women of social classes IV/V could be responsible for the pattern of male/female differences. The social gradient for IHD in women is much more steep than it is for men (as may be seen when either social classes, socioeconomic groups, or occupation orders are examined), and high rates in classes IV/V would have the effect of increasing the overall female IHD mortality with an apparent low rate in classes $\mathrm{I} / \mathrm{II}$. There may be particular risks for women married to men in unskilled jobs-perhaps related to lifestyle. The observation of high risk to women of classes IV/V does not help to identify reasons for men to have higher absolute rates of IHD than women.

Examination of the socioeconomic groups and occupation orders has done little to help in the further identification of groups at risk, and has mainly confirmed that the occupations going to make up social classes I and II have an increased risk of IHD relative to their wives despite a low rate relative to other men, whereas women married to men in unskilled occupations have high rates relative to their husbands. A more detailed examination of individual occupations might be profitable but would suffer from problems of small numbers.
Of course, women may also work, and they may have their own occupational hazards, as discussed by Fox and Adelstein. ${ }^{4}$ Women married to men of social class I are less likely to have a class I occupation themselves, ${ }^{3}$ and are thus "promoted" up the social scale by being classified by their husband's occupation rather than their own. This strengthens the idea that the described male excess may be due to a hazard associated with class I type occupation.

Where men have higher disease rates relative to other men, this is easy to discover when occupation-specific disease rates are examined-for example, members of the armed forces have high SMR for IHD, and a detailed study has indicated that soldiers are at a particular risk. ${ }^{8}$ The use of the male:female ratio suggests a risk for IHD in groups of men who have low rates compared with other men, and that without an increased risk given them by something associated with their occupation their IHD rates might be lower still. Thus a search for possible lifestyles associated with what goes on at work in men of social classes I and II rather than home might help to identify aetiological agents for IHD. Among the known candidates that might be considered are lack of exercise and different dietary, alcohol, or smoking habits. Stress at work is another possibility. Type A behaviour may be determined by occupational exposure (as there is a strong social class gradient for this behaviour pattern in men but not in women). ${ }^{9}$ Perhaps the enigma of type A behaviour predicting IHD despite being more prevalent in social classes $I$ and $\mathrm{II}^{10}$ is understandable in the context of our suggestion of a particular occupation associated excess IHD risk for men in classes I and II. There are other aspects of the quality of working life which have been thought to put people at risk for IHD, ${ }^{11}$ and we suggest that close examination of occupation associated risks for IHD would be worth while. It may also be profitable to explore the large social gradient for IHD in women in more detail. Do class associated risk factors work differently in men and women, or are there particular lifestyle influences among women of classes IV/V which may be identified?

The social class patterns for IHD are thus complex and different from those of other diseases. The relations between social class and factors associated with work, age, and sex should be examined further. In view of the increasing excess over time of IHD in people of social classes IV and V the 1981 occupational mortality data are awaited with some trepidation.

We are grateful to Ms M Morgan and Ms M Kelson for their help and advice. 


\section{References}

${ }^{1}$ Marmot MG, Adelstein AM, Robinson N, Rose G. Changing social-class distribution of heart disease. $\mathrm{Br}$ Med J 1978; ii: 1109-12.

${ }^{2}$ Halliday ML, Anderson TW. The sex differential in ischaemic heart disease: trends by social class 1931 to 1971. J Epidemiol Community Health 1979; 33: 74-7.

${ }^{3}$ Office of Population Censuses and Surveys. Occupational mortality. Registrar General's decennial supplement for England and Wales, 1970-1972. London: HMSO, 1978.

${ }^{4}$ Fox AJ, Adelstein AM. Occupational mortality: work or way of life? J Epidemiol Community Health 1978; 32: 73-8.

${ }^{5}$ Clayton DG, Taylor D, Shaper AG. Trends in heart disease in England and Wales, 1950-1973. Health Trends 1977; 9: 1-6.
${ }^{6}$ Beral V. Cardiovascular-disease mortality trends and oral-contraceptive use in young women. Lancet 1976; ii: 1047-52.

${ }^{7}$ Heller RF, Hayward D, Hobbs MST. Decline in rates of death from ischaemic heart disease in the United Kingdom. Br Med J 1983; 286: 260-2.

${ }^{8}$ Lynch P, Oelman BJ. Mortality from coronary heart disease in the British Army compared with the civil population. $\mathrm{Br}$ Med $J$ 1981; 283: 405-7.

${ }^{9}$ Robinson N, Heller RF. Experience with the Bortner questionnaire as a measure of type $A$ behaviour in the United Kingdom. Psychol Med 1980; 10: 567-71.

${ }^{10}$ Heller RF. Type A behaviour and coronary heart disease. Br Med J 1979; ii: 368.

${ }^{11}$ Opit LJ, Salzberg MR. Coronary heart disease, prevention, and work factors. Lancet 1983; ii: 289. 